\title{
PESAN MORAL DALAM MITOS PERKAWINAN LELUHUR DAYAK NGAJU
}

\author{
Sihung ${ }^{l}$
}

\begin{abstract}
Abstrak
Mitos perkawinan leluhurnya zaman dulu, bagi umat Hindu Dayak Ngaju sekarang dijadikan sebuah ilustrasi dalam menyikapi hidupnya sehari-hari guna mendekati kesempurnaan hidup. Atas kesadarannya sendiri umat Hindu Dayak Ngaju sampai sekarang, apabila melangsungkan upacara pengesahan perkawinannya mengikuti tata cara yang telah ada atau menjadi tradisi setempat yakni yang dikenal dengan istilah pelek rujin pangawin. Pelek rujin pangawin ini tumbuh dan berkembang terutama dalam komunitas Hindu Kaharingan terutama suku Dayak Ngaju dalam hal menata tatanan sosial dan membina masyarakatnya agar menjadi umat, individu yang berkarakter baik, memiliki religiusitas yang tinggi.

Dengan memahami ide, makna cerita dalam mitos tersebut umat/masyarakat penganutnya memiliki kesadaran, menempatkanya sebagai umpan balik (put back), cerminan atau sebuah pembelajaran bahwa apabila melakukan perbuatan yang bertentangan dengan norma-norma kemanusiaan ( baik yang bersumber dari ajaran agama dan adat istiadat) akan mengakibatkan hal yang tidak baik pula, dan peneyesalan tidaklah mengubah hasil yang didapat. Agar mendapatkan sesuatu tentu harus dilakukan dengan cara yang baik pula. Petunjuk Tuhan yang Maha Esa (Ranying Hatalla) memerintahkan kepada umatnya agar melakukan perbuatan yang sesuai dengan firman-Nya, khususnya bagi orang yang menikah sejak awal merencanakan perkawinan dan selama menjalani hidupnya.
\end{abstract}

Kata kunci:pesan moral, mitos perkawinan, leluhur Dayak Ngaju

\footnotetext{
${ }^{1}$ Penulis adalah Dosen Jurusan Dharma Duta STAHN-TP Palangka Raya
} 


\section{Pendahuluan}

Keragaman adat budaya pada masyarakat bangsa Indonesia menjadikan bangsa ini besar, berwibawa dan sangat berbeda dari suku bangsa disekitarnya, sehingga semboyan Bineka Tunggal Ika patut dan terus dimaknai digali seluas mungkin arti maksudnya. Kebinekaan yang dimaksud salah satu dimiliki oleh orang Dayak Ngaju tentang tata, aturan, adat perkawinan yang masih diberdayakan/dipertahankan sampai sekarang. Keberadaan tata upacara, aturan, adat perkawinan tersebut tidak lepas dari jasa baik, perhatian, pemikiran berlian dari para leluhurnya dimasa lalu. Buah pikir, pandangan, perhatian orang tua/nenek moyang dalam membina, mendidik para penerusnya agar memiliki karakter yang baik, manusiawi, memiliki religusitas yang t ing g i d i u j u d kan d a n ditransformasikan dalam bentuk mitos. Maka mitos pada umat Hindu Dayak Ngaju menjadi salah satu media pembelajaran dalam lingkungan keluarga (terutama sebelum orang Dayak Ngaju mengenal dibangku sekolah) yang diwarisi dari leluhurnya karena ide cerita (sebuah mitos), dipandang mampu memberikan gambaran atau menjelaskan asfek alamiah tentang sistem sosial, pandangan ideal suatu masyarakat penganut/empunya cerita tersebut dalam menyikapi fenomena hidup dan keinginan menciptakan masa depan yang lebih baik. Pemahaman mitos demikian berawal dari pengertian mitos (bahasa Yunani) atau mite (dalam bahasa Belanda) yang diartikan sebagai cerita prosa dimasa lampau yang sebagian besar dianggap pernah terjadi oleh penganutnya.

Orang Dayak Ngaju terutama penganut/umat Hindu sekarang dapat disebut masyarakat penganut cerita tradisional karena memiliki dan menempatkan ide beberapa mitos/cerita atau foklor tentang kejadian masa lalu menjadi latar belakang alasan kuat pelaksanaan ritual (agama) serta aturan adat dimasyarakatnya dengan tidak mengesampingkan sistem pendidikan formal di masa sekarang. Hal demikian senada dengan pendapat Danandjaya (1997:2 - 6) bahwa untuk mengkaji fisik manusia dan segala bentuk budayanya misalnya bahasa, adat istiadat, tari-tarian, alat musik dan sejenisnya dapat ditemukan melalui foklor atau cerita lisan yang mereka ketahui dan warisi secara turuntemurun.

Kemudian menurut Ratna (2004;67), mitos adalah cerita anonim yang berakar dalam kebudayaan primitive. Apa bila mitos pada awalnya diartikan sebagai imajinasi yang sederhana dan primitive untuk menyusun suatu cerita, maka dalam 
pengertian modern mitos adalah struktur cerita itu sendiri. Sebagai cerita yang mempunyai struktur maka mitos dibangun oleh satuan-satuan minimal yang bermakna. Satuan minimal yang membangun struktur cerita mitologis sehingga struktur itu sendiri mengandung makna. Junus $(1981 ; 90)$ menjelaskan bahwa hubungan mitos dengan realita kehidupan masyarakat pendukungnya, sangat dekat tergantung pada cara pandang seseorang, mitos-mitos bagi masyarakatnya berjasa untuk membatasi segala tindak-tanduknya. Ketakuatan dan keberanian terhadap sesuatu ditentukan oleh mitos-mitos disekitarnya. Banyak hal yang sukar dipercaya dapat berlaku hanya karena penganutnya mempercayai mitos, dan kehadiran mitos dalam kelompok masyarakat merupakan keharusan pada hal-hal yang bersifat abstrak yang berhubungan dengan hal/sifat baikburuk, suatu yang ambiguous.

Seorang Antropolog sosial yaitu B Malinowski (dalam William A. Lessa dan Evon Z 1997;101) menjelaskan bahwa mitos sebagaimana yang ada di masyarakat primitive, bukanlah sematamata cerita yang dikisahkan untuk pengantar tidur anak-anak, tetapi sebagian merupakan kenyataan sebagai peristiwa yang harus dimaknai. Mitos memiliki kemampuan mengaktifkan daya kehidupan masyarakat primitive, atas dasar "realitas' mitos dapat dikatakan menjadi penghubung intuisiintuisi sosial yang ada.

Umat Hindu Dayak Ngaju memiliki peradaban yang sebagian besar dilatarbelakangi oleh cerita tentang kejadian dimasa lalu/mitos. Memang diakui bahwa untuk membuktikan jejak peninggalan peristiwa dalam sebuah mitos adalah sulit, namun beberapa mitos yang dikenal secara turuntemurun oleh masyarakat/umat Hindu Dayak Ngaju terutama yang berhubungan erat dengan pelaksanaan ritual diterima dan dipercayai begitu saja, tidak melalui mupakat, meminta persetujuan/pendapat masyarakatnya. Sebab ide-ide, gagasan atau pesan moral dalam mitos dapat diterima dengan akal sehat, sesuai dengan tipikal manusianya, logis dalam rangka membentuk serta membina kehidupan bersama yang baik.

Sangat disayangkan orang Dayak Ngaju sekarang cenderung memandang mitos sebagai sebuah cerita masa lalu, bentuk cerita pengantar tidur anak-anak (membual tanpa makna) dan ada juga menyatakan bahwa mitos itu adalah sebuah cerita yang dilebihlebihkan, sehingga keberadaan mitos semakin tersingkirkan. Terbukti jarang sekali anak muda/usia sekolah yang memperhatikan cerita orang tuanya di rumah pada saat menasehati dengan cara bercerita, juga pada saat seorang tokoh 
agama mau pun tokoh adat memberikan pembinaan (pandehen) yang menggunakan media mitos saa mengisi acara siraman rohani dalam kegiatan persembahyangan bersama. Agar dipahami, dimengerti dan mampu diterima oleh masyarakat umum serta menjadi sebuah inspirasi bagi para penerus Hindu Dayak Ngaju, terutama guna pengembangan wawasan tentang mitos perkawinan dalam hubunganya dengan adat budaya masyarakat setempat maka sangatlah tepat Mitos Dalam Perkawinan Umat Hindu Dayak Ngaju ini menjadi topik pembahasan dengan rumusan masalah sebagai berikut

1. Bagaimanakah mitos perkawinan pada umat Hindu Dayak Ngaju.

2. Apakah fungsi mitos

perkawinan tersebut bagi umat Hindu Dayak Ngaju.

\section{Pembahasan}

1. Mitos Perkawinan pada Umat Hindu Dayak Ngaju

Sistem atau cara merupakan bentuk tindakan yang dilakukan oleh seseorang atau sekelompok orang untuk m ew u ju dk a n / m e n un jukkan, menyampaikan, memberikan sesuatu y ang selanjutnya. Sistem pentransformasikan mitos perkawinan yang dimaksudkan dalam tulisan ini adalah cara atau tindakan yang dilakukan oleh sesepuh, tokoh/leluhur orang Dayak Ngaju sejak zaman dulu untuk menggambarkan, menjelaskan asfek alamiah (hal pokok/ inti maksud) dari cerita yang disampaikan. Mitos yang melatarbelakangi pelaksanaan perkawinan umat Hindu Dayak Ngaju secara ringkas diceritakan dimasa lalu dikutib dari Panaturan (2013: 30-35),

Pasal 6Ayat 1

Jadi pire-pire andau alem katahie Manyamei Tunggul Garing Jaanjahaunan Laut

Sahawung tangkuranan hariran mijen banama panjang pahalampi laut

Ajung ambu taretan hariran. Kalute kea Kameluh Putak Bulau JKLBKT Mijen lasang bangkirai bahenda sambung.

Terjemahannya:

Setelah beberapa hari lamanya, Manyamei Tunggul Garing Janjahunan Laut

Sahawung tangkuranan hariran (bingung dan merasakan kesendirianya)

sedang berada di dalam banama panjang pahalempai ajung ambu taretan hariran

begitu pula Kameluh Putak

Bulau JKLBKT dan keduanya berada ditempatnya masingmasing.

Pasal 6 Ayat 3 diceritakan

Eleh kangkarungut bahing suling rumbai ambun ulih kutak-kutak sinde

Pasi ulun aku hatue kanampan bunu rayung kanejek ruhung lalu duhung tunggal

Aku dia badahang ije pulang sahiy isen dia batambah due

Terjemahannya:

Suara seruling rumbai ambun 
sangat merdu sekali

katahati

dan dapat melahirkan ungkapan

Pemiliknya, kasihan diriku

seorang laki-laki

hidup sendiri tanpa siapa pun.

Pasal 6Ayat 5 selanjutnya menceritakan

Atun rangkan pakaian anan iran panyambungan sukup

ain bawi kangumbang sinjang

habinei kamangkang luyang

andau kueh ku tau mangkang

ngangkanae, kai auh suling gariding rumbai ambun

Terjemahannya:

Aku ada menyimpan pakaian lengkap tetapi pakaian ini

bukan untukku, melainkan

pakaian milik seorang perempuan

mana mungkin bisa saya pakai, demikian ungkapan seruling tersebut.

Pasal 6 Ayat 6

Nante-nanteng bengkel

Kameluh Putak Bulau JKLBKT

awi atun tarahining bahing

suling rumbai ambun puna kutak-kutak sinde

hayak paham tutu auh kangasi.

Terjemahannya:

Mendegar bunyi seruling rumbai ambun yang sangat merdu, dengan

Bersungguh-sungguh Kameluh

Putak Bulau JKLBKT mengarahkan pendengarannya

Pasal 6 Ayat 7 menceritakan:

Kangkarau kea lingu nalatai

Kameluh Putak Bulau JKLKT

madu pahiau suling gariding

bulau sangkalemu, ie hagatang mendeng

haduanan palus mampahiau suling gariding bulau sangkalemu

kangkarungut bahing puna kutak-kutak sinde janjaruman panalatai biti.

Terjemahannya:

Setelah itu timbullah keinginannya untuk membunyikan serulingnya

Maka ia langsung berdiri dan mengambil sulingnya dan meniupkannya

Ungkapan kata lewat suara serulingnya tersebut bagaikan seorang yang sedang berbicara indah dan sangat merdu.

Pasal 6 Ayat 8 diceritakan

Kuan bahing gariding bulau sangkalemu'iyoh-iyoh tingang nyahe

Hetuh tege ulun aku bawi kangumbang sinjang, habinei kamangkang luyang

Bawi tunggal dia badahang ije, habiney sahiyisen batambah due.

Terjemahannya:

Ungkapan kata melalui suara suling gariding tersebut mengatakan,

Sesungguhnya engkau adalah saudaraku, aku adalah seorang perempuan

Ada disini hidup sendiri tanpa teman siapa pun.

Singkat cerita keduanya memutuskan setelah mereka memasang pakaian yang diterimanya, untuk bertemu langsung selanjutnya hidup bersama di tempat itu.Setelah tujuh hari, tujuh malam kebersamaan mereka, pada saat sedang ditepian sungai tiba-tiba Kameluh mengalami keguguran, dan darah kotor yang keluar itu dihanyutkan di sungai, setelah beberapa waktu terdengar suara petir halilintar menggelegar, dikejauhan 
dari darah kotor tersebut berubah /menjelma menjadi seekor binatang yang cukup besar dengan wujud yang menakutkan yangselanjutnya diberi nama sarupui biha apui. Periode berikutnya sarupui biha apui menurunkan makhluk-makhluk yang memiliki sifat negativ termasuk seekor binatang/hewan misterius yang disebut tatu dahiang oleh orang Dayak Ngaju sampai sekarang. Dikemudian hari pada saat mereka berdua sedang mandi disungai, tiba-tiba Kameluh mengalami keguguran lagi, melalui proses yang sama dari darah kotor tersebut tiba-tiba menjelma seekor binatang menyerupai ular (ular malang laut). Rumpun binatang ini menurut kepercayaan umat Hindu Dayak Ngaju sampai sekarang adalah sumber dari berbagai macam penyakit yang menjelajah kehidupan manusia.

Diceritakan sebanyak 12 kali keguguran yang dialami oleh Kameluh Putak Bulau JKLBKT dan setiap darah yang keluar itu selalu menjelma menjadi berbagai wujud hewan binatang, gaib dan nyata serta tumbuhan yang ada disekitar lingkungan hidup orang Dayak Ngaju, dan sampai sekarang sebagian masih ditemukan. Sebanyak 12 kali peristiwa keguguran yang dialami oleh Kameluh Putak Bulau. Saat mengingat dan memikirnya Kameluh berkata dalam hatinya Setelah itu dia sampaikan tentang ketakutanya dalam menghadapi hari-hari berikutnya kepada pasangannya yaitu Manyamei Tunggul Garing Janjahunan Laut. Perilaku dan perbincangan mereka berdua ini diketahui oleh Ranying Hatalla kemudian diperintahkan-Nya Raja Uju Hakanduang untuk melaksanakan upacara perkawinan Kameluh Putak Bulau JKLBKT dengan Manyamei Tunggul Garing Janjahunan Laut, seperti yang dijelaskan dalam Panaturan (2013:56-57),berikut;

"Ranying Hatalla jadi mangahandak kare taluh handiai ije jadi

Injadiae tuntang kalute kea kareh taluh handiae ije injadia rahian adndau

Tinai. Hayak te kea Ie japa japan tatah: "hetuh jadi umbet katikaAKU Majadian kakare taluh handiae huang pambelum kalunen, $A K U$ manjadian Bitibereng aing KU akan manyuang pembelum ije ingahandak awi Ku'.

Terjemahannya:

Ranying Hatalla berkehendak demikian, begitu pula Ia menjadikan segala

Kehendaknya untuk masa mendatang, maka Ia berfirman "sekarang tibalah saatnya

AKU menjadikan kehidupan dunia yang AKU kehendaki,

Karena sesungguhnya kehidupan itu adalah AKU'.

Pasal 19 Ayat 3 menyatakan:

Ewen due tuh puna ilalus lunuk hakaja pating

Baringen hatamuei bumbung, awi ewen sintung

Due dapit jeha ije manak manarantang hatamunan $A K U$ 
Huang pambelum pantai danum kalunen ije puna ingahandak

Awi KU tuntang talatah panggawi te manjadi suntu akan pambelum

Pantai danum kalunen.

Terjemahannya:

Sesungguhnya mereka berdua ini adalah wujud Ku sendiri

Aku akan melaksanakan upacara perkawinannya agar mereka dapat

Memberikan keturunan serupa Aku bagi kehidupan dunia yang Aku

Kehendaki dan ini pula yang akan mereka lakukan

Pada kehidupan dunia nantinya.

Kutiban ajaran suci diatas menjelaskan kepada umatnya bahwa Tuhan (Ranying Hatalla) berfirman bahwa segala yang terjadi di dunia sejak dulu sampai sekarang dan bahkan akan datang dan dialami oleh Kameluh dengan Manyamei, semuanya telah diatur olehNya. Atas hubungan Kameluh dengan Manyamei agar disebut perkawinan dan mendapatkan anaak keturunan sesuai dengan yang diinginkannya yaitu mendapatkan anak/keturunan yang baik dan hidup mereka berdua pun tidak terombang ambing, maka wajib diupacarai sesuai dengan tutunan dariNya yang disampaikan melalui orang suci-Nya yang diberi nama Raja Uju Hakanduang Kanaruhan Hanya Basakati.

Kemudian Pasal 19 Ayat 11 dijelaskan Raja Uju Hakanduang janjaruman peteh mandehan Ranying
Hatalla Langit

Dengan Jatha Balawang Bulau malalus gawin lunuk hakaja pating

Baringen hatamuei bumbung akan Kameluh Putak Bulau JKLBKT

Terjemahannya:

Raja Uju Hakanduang menyampaikan pesan yang difirman

oleh Ranying Hatalla Langit dan

Jatha Balawang Bulau

yang ditugaskan untuk melaksanakan upacara perkawinan

Kameluh Putak Bulau JKLBKT dengan Manyamei Tunggul Garing Jajahunan Laut.

Pasal 19 Ayat 15 menyatakan;

Tunggul Garing Janjahunan laut ewen due Kameluh putak Bulau $J K L B K T$

Munduk melai hunjun garantung hayak lenge pangantau mimbing batang sawang

Tunjuk paninjuk manunjuk akan ngambu nyarurui batang sawang

Kalute kea pai mantijak batu.

Terjemahannya:

Tunggul Garing Janjahunan Laut dengan Kameluh Putak Bulau JKLBT

Duduk diatas gong, tangan kanannya memegang pohon endong

Telunjuknya diluruskan menunjuk keatas

Kemudian kakinya menginjak batu.

Pasal 19 Ayat 16 menyatakan;

Raja Uju Hakanduang manyaki ewen sintung due mahapan

dahan bawui samben, dahan manuk darung tingang, manitis undus, meteng lilis lamiang manas sambelum hayak manjuluk pantar pinang.

Terjemahannya:

Raja Uju Hakanduang 
melaksanakan ritus penyucian hubungan perkawinan tersebut dengan cara memoles (manyaki) darah babi, darah ayam

Minyak kelapa, mengikat seuntai manik-manik Cina (lilis lamiang)

Memberikan kinangan.

Umat Hindu Dayak Ngaju khususnya saat ditanyakan alasan mereka patuh dan tetap mengikuti tata upacara, patuh dalam pemenuhan syarat adat kawin (secara materi) dalam rangka pengesahaan perkawinannya. Mengikuti tata cara yang lama yang dianjurkan oleh orang tua atau leluhurnya, dan mengaku menjadi adat istiadat dari masa leluhurnya, dan bahkan mereka sangat percaya bahwa cara itu adalah yang dipandang benar karena sesuai dengan yang diinginkannya. Berhubungan dengan pandangan dan jawaban umat sekitar, Bajik (wawancara 12 Februari 2017) menggaris-bawahi, bahwa tata cara upacara dan adat istiadat perkawinan umat Hindu Dayak Ngaju (Hindu Kaharingan) sampai sekarang yakni mengacu atau berpedoman pada pelek rujin pangawin. Dijelaskan pula oleh Bajik, bahwa istilah pelek rujin pangawin ini ditemukan dalam Panaturan (sumber tertulis ajaran Hindu Kaharingan).

Tek pelek rujin pangawin mengisi lembaran ajaran suci Panaturan, hal ini menambah kepercayaan umat Hindu Dayak Ngaju menjadi suatu keyakinan bahwa pelek rujin pangawin tersebut merupakan petunjuk Tuhan Yang Maha Esa (Ranying Hatalla). Kemudian Bajik, w awancara 27 Februari 2017) menjelaskan pelek rujin pangawin merupakan petunjuk teknis pelaksanaan perkawinan, dan menjadi tradisi secara turun-temurun pada umat Hindu Dayak Ngaju dan dapat ditemukan dalam Panaturan. Kenyataan ini tidak jauh berbeda dengan penjelasan Dhurkeim (dalam Danniel L, Pals, 2001:160) tentang kepercayaannya bahwa setiap umat manusia dalam kelompoknya agar bisa hidup berdampingan wajib memiliki moralitas yang tinggi yang dijiwai oleh norma agama (yang diyakininya) selanjutnya menjadi standarisasi penilaian perilaku bagi semua anggota kelompok.

\section{Fungsi mitos}

Umat Hindu Dayak Ngaju sekarang adalah penerus adat istiadat leluhurnya, dan memiliki tugas serta tanggung jawab utama yaitu melestarikan, mempertahankan dan mengangkat identitas agama dan adat budaya tersebut serta menggali arti maknanya, memanfaatkanya guna memenuhi kebutuhan hidup mereka agar damai, sejahtera. Hal ini senada dengan makna budaya menurut Arnold dan pengikutnya (dalam John Hartley, 2010:31) merupakan cara untuk mencari 
kesempurnaan dan bukan bersifat material melalui pengetahuan dan praktik karya sastra "tinggi' seni murni dan musik serius. Pada era globalisasi ini adat budaya yang masih lestari dan masih eksis pada masyarakatnya digolongkan sebagai sebuah kearifan lokal. Salah satu kearifan lokal orang Dayak Ngaju dikenal dengan pelek rujin pangawin. Ide gagasan pelek rujin pangawin dalam perbendaharaan pikiran, kepercayaan umat/ masyarakatnya demikian lama hidup dan kuat mempengaruhi pola laku mereka sehari-hari. Hal ini menunjukkan bahwa bentuk perilaku (yang diimplementasi dalam bentuk tata cara upacara pengesahan perkawinan) bukan semata sebagai potret pengalaman, namun juga merupakan kreasi antara pengalaman dengan pemahaman mereka terhadap mitos perkawinan yang mereka pahami yang memunculkan konsep pelek rujin pangawin. Tujuan pengkreasian tersebut adalah agar fungsi ajaran dalam pelek rujin pangawin atau yang disebut dengan arti makna, nilai, dianut dengan penuh kesadaran dan dirasakan sebagai suatu kebutuhan dalam hidup masyarakat/umatnya.

Setelah memperhatikan pandangan dan kepercayaan masyarakatnya (umat Hindu Dayak Nagju) tentang mitos perkawinan ini dapat disimpulkan bahwa mereka menyetarakan mitos dengan sejarah/historis yang dibentuk oleh masyarakat pada zaman dulu. Hal ini relevan dengan pengertian mitos oleh Roland Barthes, yakni sebagai tuturan mitologis bukan saja berbentuk tuturan oral, tetapi tuturan yang dapat berbentuk tulisan, fotografi, film, laporan ilmiah, olah raga, pertunjukan, iklan, lukisan, dan pada dasarnya adalah semua itu mempunyai modus representasi serta mempunyai arti (meaning) yang belum tentu bisa ditangkap secara langsung, misal; untuk menangkap arti atau meaning sebuah lukisan diperlukan interpertasi. Pada dasarnya tradisional (antara lain yaitu umat Hindu Dayak Ngaju) memandang atau mengganggap bagai dongeng suci ataupun legenda, sering kalisecara tidak langsung dianggap sebagai doktrin atau dianggap pesan yang datang dari Tuhan, sehingga tidak perlu dipertanyakan secara kritikal. Keyakinan terhadap mitos tersebut menjadikan mitos sebagai sarana pendidikan yang paling efektif terutama untuk mengukuhkan dan menanamkan nilai-nilai budaya, normanorma sosial dan keyakinan tertentu. Selanjutnya mitos juga dimanfaatkan sebagai pegangan bagi masyarakat pendukungnya untuk membina kesetiakawanan sosial diantara para anggotanya. Demikian halnya beberapa sekte-sekte agama di Indonesia telah memegang teguh mitos tertentu, 
sehingga mereka dapat saling membedakan antara komunitas yang satu dan yang lain.

Berkaitan dengan fungsi mitos sebagai sarana pembelajaran, maka tidaklah mengherankan jika dongengdongeng yang bernafaskan petuah atau mengarah pada nilai-nilai moral/ etika "suci" yang terdapat pada setiap komunitas, berfungsi sebagai peraga untuk mempererat keyakinan masyarakat terhadap keluhuran budayanya dan memperkokoh kesetiawanan sosial mereka seperti yang tersirat dalam dongeng-dongeng suci yang berkembang di masyarakat. Masyarakat Dayak Ngaju sudah mampu menyerap pesan-pesan budaya dengan tanpa merasakan kejemuan. Contoh nyata dalam mitos perkawinan Kameluh Putak Bulau Janjulen Karangan Limut Batau Kamasan Tambun dengan Manyamei Tunggul Garing Janjahunan Laut menyampaikan pesan moral kepada masyarakatnya bahwa perbuatan manusia yang melanggar atau mengabaikan etika susila hidup beragama dan berbudaya akan berakibat yang tidak baik,dan sangat merugikan individu yang bersangkutan.

Tuturan dalam bentuk mitos perkawinan ini dibuat untuk mengkomunikasi tatanan sosial masyarakatnya yang dibangun dalam koridor ajaran agama Hindu (Dayak
Ngaju) dan dapat diterima oleh akal sehat. Umat Hindu Dayak Ngaju sebagai makhluk yang berbudaya/ berada dalam lingkup sosial budaya, dan senantiasa berusaha untuk memahami diri dan kedudukannya dalam alam semesta serta menentukan sikap/ tindakannya untuk mengembang-kan kehidupannya, mengembangkan caracara yang bersifat komunikatif untuk menjelaskan berbagai perasaan yang mempunyai arti bagi kelangsungan hidupnya. Tujuannya untuk menyempurnakan spiritual mereka yang diawali dengan keteraturan, ketentraman dalam hidup berumah tangga, menjadi anggota masyarakat dan sebagai umat beragama yang baik.

Berabad-abad lamanya pelek rujin pangawin dijadikan pedoman, panduan atau sebuah petunjuk dalam menata sistem pengesahan perkawinan masyarakat pendukungnya, dan telah menunjukkan kemampuannya dalam menata sistem sosial menyangkut hubungan kekerabatan, dan membentuk karakter masyarakatnya, kemudian dengan disahkannya Undang Undang Perkawinan tahun 1974 tidak ada pertentangan atau pun perubahan terhadap tradisi dan adat perkawinan umat Hindu Dayak Ngaju tersebut. Fenomena inilah memperkuat kepercayaan bahwa peristiwa yang diceritakan (dalam mitos tersebut) dipercaya memang terjadi di masa yang 
lalu dalam kehidupan leluhurnya. Kemudian hal-hal yang dialami oleh Kameluh Putak Bulau Janjulen Karangan Limut Batu Kamasan Tambun dan Manyamei Tunggul Garing Janjahunan Laut tersebut mampu menjadi pembelajaran bagi penganutnya, karena gagasan mitos itu (makna cerita) menggambarkan hasil perbuatan/tindakan yang berhubungan dengan sebab dan akibat (menurut pandangan ajaran agama yang bersangkutan). Umat Hindu Dayak Ngaju sampai sekarang menganggap dan menempatkan kedua pigur dalam mitos itu menjadi leluhur mereka. Anggapan dan kepercayaan inilah yang membangun kedekatan (hubungan secara batiniah) umat Hindu Dayak Ngaju atau umat Hindu Kaharingan sekarang terhadap Kameluh Putak Bulau dan pasangannya yaitu Manyamei Tunggul Garing dan keturunannya sehingga mengakui dan percaya pasangan tersebut adalah leluhurnya.

Bertolok pada kebiasaan orang Dayak Ngaju zaman dulu (masa pra tulisan) menjadikan mitos atau ceritacerita daerah menjadi salah satu media pembelajaran yang dipandang efektif dalam memberikan penyadaran kepada setiap anak dalam keluarga untuk wajib melakukan perbuatan baik dan menghindari perbuatan yang tidak baik atau bertentangan dengan norma kemanusiaan. Dengan demikian dapat dikatakan bahwa melalui penceritaan mitos itu diharapkan mampu membangun kecerdasan intelektual pada pendengarnya atau penganutnya. Hasil pengamatan dan pengalaman penulis dilingkungan keluarga orang Dayak Ngaju bahwa pembentukan karakter atau pembinaan moral pada anak-anak adalah sangat utama sehingga dilakukan sejak awal dimulai dari pembentukan keluarga (dilegalkannya hubungan suami istri) dengan melibatkan ajaran agama, etika susila. Tujuan pelibatan dua hal tersebut adalah untuk mendapatkan ketentraman batin, berupaya memahami arti makna suci, sakral dalam kehidupan jasmaniah, dan adat istiadat (membentu pembentuk mental moral) individu.

A jaran agama $\mathrm{Hindu}$ Kaharingan (bagi orang Dayak Ngaju) dalam bentuk mitos perkawinan juga menyediakan ruang kepada umatnya/penganutnya untuk melakukan pemujaan, pelibatan arti suci dan sakral dalam perkawinannya sehingga perkawinan itu disebut sah secara agama. Kemudian sebagai anggota masyarakat orang yang menikah harus manut terhadap adat istiadat/tatanan sosial yang berlaku, mengerti dan memahami status sosialnya agar mampu menempatkan dirinya ditengah masyarakat, lingkungannya serta bisa menghargai hak orang lain, bertanggung jawab atas dirinya sendiri, jujur, setia 
dengan pasangannya. Peristiwa dimasa lalu, menggambarkan perilaku pasangan yang dijadikan tokoh/lakon cerita tersebut yang pada saat itu mereka melakukan perbuatan yang dinilai tidak benar karena bertentangan dengan norma agama dan adat istiadat. Sehingga setelah beberapa rentang waktu hal-hal yang dialaminya melalui renungannya, mereka berdua merasa sangat dirugikan. Penekanan dalam cerita tersebut yakni Kameluh Putak Bualu merasa bingung dan kecewa karena keinginannya untuk mendapatkan anak dari perkawinannya dengan Manyamei Tunggul Garing Janjahunan Laut ternyata tidak terwujud.

Menurut keyakinan umat Hindu Kaharingan hal demikian telah diatur oleh Tuhan Yang Maha Esa (Ranying Hatalla), dan harus terjadi sesuai dengan kehendak-Nya. Sehingga pada saat yang tepat beliau mengutuskan orang suci-Nya yang diberi gelar Raja Uju Hakanduang untuk memberitahukan, dan menjelaskan kepada mereka berdua untuk segera melaksanakan pengesahan perkawinannya dengan mengikuti petunjuk, Ranying Hataalla. Tata cara upacara penyucian/penyakralan perkawinan pada umat Hindu Kaharingan/Hindu Dayak Ngaju sesuai dengan martabat manusia (adat istiadat) yang selanjutnya disebut pelek rujin pangawin. Periode berikutnya mitos yang melatarbelakangi munculnya pelek rujin pangawin ini ditulis dalam Panaturan (sumber tertulis ajaran Hindu Kaharingan), maka tepatlah pelek rujin pangawin tersebut disebut aturan adat perkawinan umat Hindu Kaharingan atau umat Hindu Dayak Ngaju.

Atas kesadarannya sendiri, umat Hindu Dayak Ngaju dalam setiap pengesahan perkawinannya (membentuk rumah tangganya) terpanggil atau merasa wajib mengikuti, mematuhi tata cara, aturan yang telah dikemas dalam konsep pelek rujin pangawin. Ajaran dalam pelek rujin pangawin menata, mengontrol sikap sebagai suami istri dalam rumah tangganya, sebagai anggota masyarakat, adat dan agama dan sebagai orang tua. Sejak awal anak (usia dini) mulai dari dalam rumah/lingkungan keluarga dibiasakan untuk melakukan hal yang sama misalnya dengan lebih dulu menyapa orang yang lebih tua, meminta maaf dengan teman sepermainanya, mendengarkan cerita orang tua atau kakek neneknya, wajib menghormati orang lain. Setelah dewasa, dan akan menikah anak, diwajibkan memberitahukan orang tuanya, keluarganya, karena terjadi perkawinan maka terjadi pula hubungan persaudaraan antara pihak suami dan pihak istri. Untuk itulah mereka yang menikah wajib bekerjasama dan menyerahkan prosedur pelaksanaan 
secara adat, agama.

Gazali (2012:50), menyatakan bahwa upacara atau ritual merupakan wahana, cara yang dilakukan oleh manusia untuk melakukan suatu transformasi, kemudian Susane Langer (dalam Davamony, 1995:174) menegaskan bahwa upacara cenderung sebagai sebuah pernyataan yang bersifat logis. Jadi, upacara sebagai bentuk perbuatan baik yang berhubungan dengan penilaian dari aspek mental, moral manusia dan tindakan atau aktivitas sebagai upaya manusia untuk menghubungkan diri dengan Tuhan. Lebih lugas lagi Wijayananda (2004:49) mereferensikan pengertian upacara dari bahasa Sanskerta dari urat kata upa yang berarti 'mendekat' dan cara dari akar kata'car' yang berarti 'harmonis, selaras, seimbang. Jadi, upacara adalah suatu tindakan yang menjadikan keadaan seimbang, selaras, harmonis dalam diri guna mendekatkan diri dengan Tuhan Yang Maha Esa.

Pernyataan, referensi, mau pun penjelasan oleh beberapa sarjana tentang upacara tersebut tidak terlepas dari tujuan pelaksanaan upacara perkawinan menurut kepercayaan umat Hindu Dayak Ngaju sampai sekarang. Tindakan upacara pengesahan perkawinan pada umat Hindu Dayak Ngaju yang sangat istimewa adalah bertujuan mereidentifikasi (mereka ulang perilaku Raja Uju Hakanduang Kanaruhan Hanya Basakati sebagai orang suci Ranying Hatalla pada masa lalu pada acara pengesahankan dan menyakralkan hubungan sebagai suami istri antara Kameluh Putak Bulau dengan Manyamei Tunggul Garing. Dengan perlakuan ini terungkaplah kembali peristiwa yang sangat menyejarah dalam pembentukan dan penerapan norma, aturan adat istiadat perkawinan/rumah tangga dan tatanan sosial orang Dayak Ngaju.

Norma, aturan dalam perkawinan umat Hindu Dayak Ngaju direfensikan dalam bentuk istilah, nama barang atau benda, alat, misalnya; Ranying Hatalla Katamparan, Langit Katambuan (referensi dalam bentuk istilah lokal), emas perhiasan (bulau singah pelek), kain panjang (sinjang entang), dan yang lainnya (referensi dalam bentuk benda). Benda atau barang mau pun istilah yang dilibatkan dalam konsep pelek rujin pangawin itu sendiri semata sebagai acuan yang memiliki makna, arti atau maksud masing dalam kontek kehidupan berumah tangga tersebut. Pengkemasan aturan, norma perkawinan dalam pelek rujin pangawin yang menggunakan atau direferensikan dalam bentuk ungkapan/istilah, nama barang atau benda tersebut oleh kaum penggagas pada waktu itu dipandang tepat untuk mentransformasikan pesanpesan yang ingin disampaikan. Sehingga 
umatnya sampai sekarang diinginkan atau diharapkan memahami dan mengenali arti makna pesan yang diemban atau yang tersimpan dibalik benda, barang atau istilah yang dilibatkan dalam konsep pelek rujin pangawin tersebut.

Pada periode berikutnya ternyata barang atau benda yang direfernsikan sebagai jalan hadat kawin dalam tradisi perkawinan umat Hindu Dayak Ngaju mengalami kelangkaan sehingga agar tetap berlangsungnya sistem perkawinan sesuai dengan pedoman dan tata cara yang telah mentradisi maka sebagian dari benda yang harus diserahkan untuk pemenuhan jalan hadat kawin disepakati pada hari pertunangan diganti dengan benda yang lain dengan tidak merubah konsep semula. Dipertahankannya pelek rujin pangawin bertujuan untuk tetap mempertahankan arti, makna yang dimaksudkan dalam istilah yang digunakan yang diwakili oleh benda pemenuhan Jalan hadat kawin. Artinya istilah, ungkapan atau pun nama benda barang yang dilibatkan dalam konsep pelek rujin pangawin tersebut berkedudukan sebagai simbol-simbol yang dijiwai oleh aturan, norma atau tata laku, atau sikap sebagai suami dan istri dalam satu rumah tangga, dan sebagai warga masyarakat. Dari awal merencanakan upacara perkawinannya umat Hindu Dayak Ngaju sudah diwajibkan mengikuti dan mematuhi aturan norma sosial yang diberlakukan yang tujuannya menyadarkan individu bahwa keharmonisan dapat tercipta dalam diri dimulai dari diri sendiri, dan kepribadian yang baik adalah sumber kebahagiaan.

Adat dan ajaran agama adalah dua hal yang berbeda tetapi kedua hal ini apabila digunakan secara metodis untuk membangun struktur kehidupan berumah tangga dengan baik dan tepat maka akan menghasilkan keluarga, rumah tangga yang damai, cinta yang abadi hidup sejahtera lahir batin (belum tatau sanang, hakambelum sampai hentang tulang hinje sandung mantang). Seperti cerita kehidupan keluarga Manyamei Tunggul Garing Janjahunan Laut dengan istrinya Kameluh Putak Bulau Janjulen Karangan Limut Batu Kamasan Tambun bahwa setelah dilaksanakan pengesahan perkawinannya dengan mengikuti petunjuk-Nya, lalu mereka berdua mempunyai anak dan dengang bahagia mengamati perkembangan anakanaknya sampai dewasa memiliki, mewarisi karakter yang baik. Dengan demikian dapat dinyatakan dari segi praktik beragama, umat Hindu Dayak Ngaju dapat dipastikan telah mampu menyerap pesan-pesan budaya yang berkembang sesuai dengan zamannya 


\section{Kesimpulan}

1. Mitos perkawinan Kameluh Putak Bulau JKLBKT dengan Manyamei Tunggul Garing Janjahunan Laut bagi generasinya merupakan penggambaran pengalaman, pengetahuan para leluhur zaman dulu dan menjadi ilustrasi pada generasinya dalam menyikapi kehidupannya masa sekarang dan mendatang agar lebih baik dan sempurna.

2. Sebagai sebuah kearifan lokal, ide gagasan dalam mitos perkawinan yang memunculkan konsep pelek rujin pangawin harus dimasyarakatkan sebab arti makna dalam konsep pelek rujin pangawin tersebut menyadarkan umat manusia selama hidup didunia sebagai suami istri dan masyarakat wajib membina hubungan baik dengan sesama, membina hubungan baik dengan alam dan terhadap yang dipuja.

\section{Daftar Pustaka}

Daniel L. Pals, 2001. Seven Theories of Relegion. Dari animisme E.B Tylor, Materialalisme Karl Marx, hingga Antropologi Budaya C. Geertz. Qalam. Yogyakarta.

Koentjaraningrat, 1997
William A. Lessa dan Evon Z Vogt yang

berjudul Reader In Comparative

Relegion (1997

Ghazali, A Muhtar. 2011. Antropologi Agama. Upaya Memahami Keragaman Kepercayaan Keyakinan Dan Agama. Bandung. Alfabeta.

John Hartley, 2010. Communication, C ultural dan Media Studies. Yogyakarta. Jalasutra.

Tim , 2013. Panaturan. Majelis Besar Agama Hindu Kaharingan (MBAHK) Pusat Palangka Raya. Widya Dharma Denpasar.

Dhavamony, Mariasusai. 1995. Fenomenologi Agama. Yogyakarta. Kanisius. 
Jurnal Dharma Duta 2017 VOL XV, Januari - Juni 2017 